\title{
Mobile learning e o uso de apps como proposta para o ensino de Ciências
}

\author{
Pâmella Dutra* \\ Paula Vanessa Bervian** \\ Roque Ismael da Costa Güllich***
}

\begin{abstract}
Resumo
Este artigo apresenta reflexões sobre a mobile learning e o uso de apps para a elaboração de estratégias de ensino para os professores de Ciências. Temos como intuito publicizar a análise desenvolvida de apps, gratuitos e em língua portuguesa, que podem ser utilizados nas aulas de Ciências e Biologia da Educação Básica. Realizamos um levantamento na loja de apps da Google Play Store ${ }^{\circledR}$, com a palavra-chave: "Biologia". Após a identificação e análise, encontramos 42 apps potenciais para o Ensino de Ciências em contexto escolar. Estes foram categorizados de acordo com a tipologia (vídeo ou animação, simulador, conjunto de exercícios, material de consulta de informações, livro ou outro); nível de ensino (Ensino Fundamental anos iniciais ou anos finais e Ensino Médio); temática e conteúdos. Os apps abordam as seguintes temáticas e conteúdos: Anatomia e Fisiologia Humana (Sistema Nervoso, Sistema Digestório, Sistema Circulatório, Sistema Locomotor, Sistema Respiratório); Biologia Celular (Célula Procarionte, Eucarionte, Vegetal, Animal e Bacteriana) e Taxonomia dos Seres Vivos. Visamos a contribuir para o desenvolvimento de novas experiências educativas e formativas, pois compreendemos que pelo uso de novas estratégias de ensino, com base nas tecnologias digitais, nos processos de ensino e aprendizagem, o professor também se constitui e (re)significa sua docência.
\end{abstract}

Palavras-chaves: estratégias de ensino, aprendizagem móvel, tecnologias digitais, ensino de Biologia.

\section{Mobile learning and the use of apps as a proposal for teaching science}

\section{Abstract}

This article presents reflections about mobile learning and the use of apps for the elaboration of teaching strategies for Science teachers. We intend to publicize the developed analysis of free apps and portuguese language that can be used in Basic Science and Biology classes. We conducted a survey on the Google Play Store ${ }^{\circledR}$ apps store with the keyword: "Biology". After identification and analysis, they resulted in 42 potential apps for Science teaching in a school context. These were categorized according to the typology (video or animation, simulator, set of exercises, information material, book or other); level of education (elementary school years or final years and high school); thematic and content. The apps cover the following topics and contents: Anatomy and Human Physiology (Nervous System, Digestive System, Circulatory System, Locomotor System, Respiratory System); Cellular Biology (Prokaryotic, Eukaryotic, Plant, Animal and Bacterial Cells) and Taxonomy of Living Beings. We aim to contribute to the development of new educational and training experiences, as we understand that by using new teaching strategies, based on digital technologies, teaching and learning processes, the teacher also constitutes and (re) means his teaching.

Keywords: teaching strategies, mobile learning, digital technologies, biology teaching.

\footnotetext{
* Licenciatura em Ciências Biológicas pela Universidade Federal da Fronteira Sul - UFFS - Campus Cerro Largo-RS. E-mail:pamidutra27@gmail.com.

** Doutora em Educação nas Ciências (UNIJUÍ) e professora da Universidade Federal da Fronteira Sul UFFS - Campus Cerro Largo-RS. E-mail: paula.bervian@uffs.edu.br.

***** Doutor em Educação nas Ciências (UNIJUÍ) e professor da Universidade Federal da Fronteira Sul UFFS - Campus Cerro Largo-RS. E-mail: bioroque.girua@ gmail.com.
} 


\section{Introdução}

Temos como premissa que a formação de professores acontece num diálogo sobre o desenvolvimento do currículo. Ao assumirmos esta intrínseca relação, compreendemos a necessidade de articulação entre formação inicial docente e o contexto concreto da Educação Básica, bem com o vínculo entre as pesquisas acadêmicas com as questões relacionadas à Escola. A pesquisa foi desenvolvida nesse movimento formativo, num momento no qual a temática "tecnologias digitais (TD) no ensino de ciências" passou a ser intensamente problematizada em nosso grupo de pesquisa ${ }^{1}$ e em nossas aulas nas práticas de ensino e nos estágios curriculares supervisionados.

Em consonância com as diretrizes curriculares e os incentivos em editais de pesquisa de iniciação tecnológica e inovação, a saber: Fundação de Amparo à Pesquisa do Estado do Rio Grande do Sul (FAPERGS) e do Conselho Nacional de Desenvolvimento Científico e Tecnológico (CNPq). Neste processo, nossos professores em formação inicial desenvolveram planejamentos em seus estágios com as TD como estratégias de ensino e outros, a exemplo deste artigo, realizaram pesquisas acadêmicas sobre a temática. Neste artigo, refletiremos especificamente sobre o uso das tecnologias da informação móveis e sem fio (TIMS), dos $a_{p p s}{ }^{2}$, dispositivos móveis e da mobile learning ${ }^{3}$ em contexto educativo.

A mobile learning, modalidade de ensino emergente, refere-se aos processos de ensino e aprendizagem com mobilidade, possibilitando aos professores e alunos estar física ou geograficamente distantes uns dos outros ou em sala de aula (SCHLEMMER et $a l .$, 2007). Esta mobilidade do espaço físico está atrelada à mobilidade dos conteúdos, ao ultrapassar aspectos referentes às relações sincrônicas e assincrônicas, transformando as relações espaço-temporais. Estas transformações possibilitam a construção de novas estratégias de ensino, ao modificar as relações entre professores e alunos nos processos de ensino e aprendizagem. Este movimento acarreta impactos sobre a própria atuação

\footnotetext{
${ }^{1}$ Citamos o Grupo de Estudos e Pesquisa em Ensino de Ciências e Matemática (GEPECIEM).

${ }^{2}$ Utilizamos a abreviatura de aplicativos móveis que são softwares desenvolvidos para dispositivos móveis (smartphones, tables, ipads entre outros), amplamente utilizada.

3 Termo sinônimo: m-learning em referência a e-learning. Traduções utilizadas por pesquisadores brasileiros: aprendizagem móvel ou aprendizagem com mobilidade. De acordo com nosso posicionamento teórico, utilizamos o termo mobile learning.
} 
docente e as condições necessárias para a docência no contexto educacional como também na formação destes professores.

Referente a estas problemáticas, esta pesquisa é oriunda de um trabalho de conclusão de curso e foi motivada com o propósito de compreender como as TIMS podem contribuir para os processos de ensino e aprendizagem no Ensino de Ciências na perspectiva da mobile learning, com o uso de apps na Educação Básica. Sobre a mobile learning, como possibilidade educativa, antes de o professor fazer uso dos apps em seu planejamento, é preciso considerar quais estão disponíveis e são viáveis para a utilização em seu contexto escolar e quais são os critérios para a sua seleção.

Partimos de uma perspectiva não tecnocêntrica sobre o uso TD na formação de professores e no desenvolvimento de estratégias de ensino. A identificação e análise dos apps presentes neste artigo segue a compreensão referente a mobile learning não ser definida simplesmente nas TIMS, mas no impacto da utilização destas nos processos de ensino e aprendizagem. A proposta de ensino com o uso de apps decorre de pesquisas criteriosas e de experiências formativas, não de uma visão simplista sobre a sua utilização, pois requer ultrapassar desafios referentes a aspectos financeiros, de infraestrutura, pedagógicos, institucionais, sociais e culturais (TRAXLER, 2012).

Compreendemos que, ao publicizarmos a análise de apps com uso potencial para as estratégias de ensino de Ciências, podemos contribuir para o trabalho docente e consequentemente para a aprendizagem dos alunos, impulsionando novas experiências educativas nos diversos contextos escolares e também formativas para os docentes. Pois o professor, ao desenvolver novas estratégias de ensino, também se constitui, (re)significando a sua docência.

Neste sentido,

o trabalho com a tecnologia exige do professor uma nova forma de educar, pois a revolução da tecnologia acontece independentemente de estar ou não em um planejamento da escola, pois os alunos que já convivem com essa tecnologia inovadora em seu cotidiano já sentem a necessidade de que escola desenvolva seu trabalho partindo dela (DARON; SOARES; BARROS, 2014, p. 479).

O artigo está estruturado nas seguintes seções: a primeira explicita os pressupostos teóricos dos autores, apresentando um breve panorama da mobile learning $\mathrm{e}$ compreensões contextuais sobre a formação de professores de Ciências atrelada ao 
desenvolvimento curricular. A segunda descreve o percurso metodológico do levantamento, monitoramento e análise dos apps para o ensino de Ciências. A terceira enuncia os resultados da discussão da análise, cotejados como proposta de utilização de apps para os professores e como necessidades formativas e educacionais da mobile learning do ensino de Ciências. Ao final, explicitamos nossas considerações e entendimentos concernentes à problemática da pesquisa.

\section{Pressupostos teóricos}

Breve panorama da mobile learning

Nos últimos anos, vários pesquisadores vêm se dedicando ao estudo da mobile learning mundialmente. Suas investigações iniciaram em 2002, num workshop no Reino Unido e, desde então, pesquisadores evidenciam possibilidades do uso de dispositivos móveis nos processos de ensino e aprendizagem em instituições educativas em contextos distintos (TRAXLER, 2012). Ao promover expansão no “[....] acesso educacional de maneiras que não eram possíveis antes; e suporta formação, administração e desenvolvimento profissional (TRAXLER; VOSLOO, 2014, p. 14 [tradução nossa]).)"

Compreendemos que, mesmo após 15 anos de intensa investigação, em contexto brasileiro a mobile learning ainda é uma temática emergente e precisa ser investigada com foco nas necessidades das instituições educativas. Especificamente no que concerne aos seus impactos no contexto educacional atrelados aos aspectos pedagógicos, conteúdos escolares, processos avaliativos, às condições de trabalho e formação dos professores (TRAXLER; VOSLOO, 2014). Tendo em vista o próprio descompasso entre as pesquisas acadêmicas, que evidenciam suas potencialidades, e a legislação ${ }^{4}$, que proíbe o uso de smartphones em sala de aula.

Apresentamos nesta seção algumas compreensões sobre a mobile learning. Porém, a sua definição ainda é considerada emergente e em construção: alguns autores enfatizam a definição em relação às TD, enquanto outros argumentam em relação à “[...] mobilidade dos alunos e da mobilidade da aprendizagem, e em termos da experiência dos aprendizes de aprender com dispositivos móveis (TRAXLER, 2007, p. 1 [tradução nossa])". Nossa compreensão vai ao encontro da segunda interpretação, assim

\footnotetext{
${ }^{4}$ Lei n. 2.246/ 2007.
} 
dialogaremos com autores que compartilham deste entendimento. Pois,

[...] é necessário que seja ampliada a visão que o professor tem sobre o uso das novas tecnologias em sala de aula. Não basta para eles apenas utilizar mecanicamente as ferramentas tecnológicas, mas também, saber para que deve usar, como usar e que impacto terá na aprendizagem do aluno (DARON; SOARES; BARROS, 2014, p. 479).

Esta modalidade de ensino tem despertado o interesse de pesquisadores brasileiros em relação à formação de professores (BARROS, 2014; NICHELE, 2015; NICHELE; SCHLEMMER, 2014;) e às estratégias de ensino no contexto educativo (ALCÂNTARA; MORAES FILHO, 2015; ALMEIDA; ARAÚJO JR; FRANÇA, 2015; FERNANDES $e t$ al., 2013; ROCHA et al., 2015). Pois, conforme Traxler (2007), serão as interpretações dos pesquisadores e professores sobre a mobile learning que terão impacto em sua implementação e, consequentemente, em sua definição. Neste sentido, são as teorias educacionais, de currículo e de formação docente que estarão relacionadas aos entendimentos sobre o trabalho com mobile learning. Por isso, na seção seguinte apresentaremos as nossas perspectivas teóricas como professores pesquisadores da área de ensino de Ciências.

\section{Contexto teórico: formação atrelada ao desenvolvimento do currículo}

Desde a sua criação, em nosso grupo de estudo e pesquisa da área de ensino de Ciências temos como pressupostos teóricos a investigação-formação-ação (GÜLLICH, 2012) e abordagem histórico-cultural na ótica dos trabalhos de Vigotski (2007). Estes pressupostos estão presentes em nossas pesquisas, em nossas aulas e nos programas de ensino e extensão com foco na formação inicial e continuada pela tríade de interação ${ }^{5}$ : licenciandos, professores da Educação Básica e Superior. Nossos esforços consistem na aproximação entre as pesquisas e a formação de professores, Educação Básica e Ensino Superior.

Neste contexto, nos últimos cinco anos, iniciamos um movimento de pesquisa e formação considerando que os professores necessitam de articular seu conhecimento pedagógico de conteúdo aos conhecimentos tecnológicos, num trabalho com as TD nas

\footnotetext{
${ }^{5}$ Termo proposto por Zanon (2003) para a interação entre os três sujeitos professores constituindo o módulo triádico.
} 
estratégias de ensino de Ciências. Ampliando a compreensão dos conhecimentos de professor, visando à constituição dos conhecimentos tecnológicos pedagógicos de conteúdo (TPACK) ${ }^{6}$ no ensino de Ciências.

Concordamos com a proposta de framework TPACK, elaborada por Mishra e Koehler (2006) e intensamente investigada. Em linhas gerais, de acordo com os autores, compreende-se que os três conhecimentos: tecnológico, pedagógico e de conteúdo, se inter-relacionam e resultam no conhecimento de professor necessário para a integração das tecnologias nos processos de ensino e aprendizagem que precisam considerar o contexto específico no qual será desenvolvido, ou seja, o conhecimento tecnológico pedagógico de conteúdo (TPACK). Depreendemos que a constituição deste conhecimento em seus processos formativos desenvolverá a elaboração de novas estratégias com as TD em contexto educativo.

Baseados na abordagem histórico-cultural, compreendemos que as TD, incluindo as TIMS, os dispositivos móveis e os apps, são instrumentos culturais apropriados na interação social e, portanto, precisam ser desenvolvidas nas institucionais educativas.

\section{Percurso metodológico: levantamento, monitoramento e avaliação de apps}

Com o intuito de identificarmos os apps potenciais na elaboração de aulas de Ciências e Biologia na Educação Básica, realizamos um levantamento na loja virtual Google Play Store ${ }^{\circledR}$, para o sistema operacional Android, utilizando a palavra-chave: "Biologia"7 acessando a opção "apps". O monitoramento foi realizado mensalmente no período de março a agosto de 2016.

Compreendemos que para viabilizar a utilização de apps na Educação Básica há duas premissas a serem consideradas: que o idioma seja em língua portuguesa e que seu download e acesso sejam gratuitos. Por isso, nosso levantamento contemplou apenas apps que atenderam a estes critérios.

Para a avaliação dos apps, utilizamos o modelo adaptado de Nichele e Schlemmer (2014), com as seguintes categorias e subcategorias: a) tipologia: vídeo ou animação, simulador, conjunto de exercícios, material de consulta de informações, livro ou outro; b)

\footnotetext{
${ }^{6}$ Sigla em língua inglesa, amplamente utilizada na literatura, para Technological Pedagogical Content Knowledge.

${ }^{7}$ Para a busca foi utilizado o smartphone da marca Samsung Galaxy Gran Prime Duos.
} 
nível de ensino: Ensino Fundamental anos iniciais ou anos finais ou Ensino Médio; c) temática; d) conteúdos. As subcategorias de "a" e "b" foram definidas antes da análise e as categorias "c" e "d" foram identificadas posteriormente e serão apresentadas na próxima seção.

\section{Resultados e Discussão}

\section{Proposta de utilização de apps para os professores de ciências}

Em nosso levantamento, encontramos 42 apps que foram avaliados e com potencial para a utilização pelos professores de Ciências e Biologia em contexto escolar numa proposta de mobile learning. Identificamos os apps de acordo com as tipologias. Porém, a maioria não está restrita a um tipo (por exemplo: vídeo ou animação; conjunto de exercícios; material de consulta de informações), o que caracteriza as possibilidades do formato multimídia (vídeo, áudio, imagem, texto entre outros). A tipologia com maior número de apps foi "Material de consulta de informações" e com menor número "Livro". Identificamos que alguns apps podem ser utilizados no planejamento de estratégias de ensino tanto no Ensino Fundamental - anos finais como no Ensino Médio. Entretanto, encontramos mais apps para o Ensino Médio (Quadro 1).

Quadro 1 - Resultados dos critérios de avaliação dos apps em língua portuguesa e gratuito, encontrados no Google Play Store ${ }^{\circledR}$, período: março a agosto/2016

\begin{tabular}{|l|l|l|}
\hline \multicolumn{1}{|c|}{ Título do App } & \multicolumn{1}{c|}{ Tipologia } & \multicolumn{1}{c|}{ Nível de Ensino } \\
\hline Passei! ENEM & Conjunto de exercícios & Ensino Fundamental Anos Finais \\
\hline ENEM 2015 & Conjunto de exercícios & Ensino Médio \\
\hline Brainly - estude com a gente & Conjunto de exercícios & $\begin{array}{l}\text { Ensino Fundamental Anos Iniciais } \\
\text { e Finais, Ensino Médio }\end{array}$ \\
\hline Bios Cursos & Conjunto de exercícios & Ensino Médio \\
\hline Biologia perguntas e respostas & Conjunto de exercícios & Ensino Médio \\
\hline Biologia de Bolso & Conjunto de exercícios & Ensino Médio \\
\hline Biologia 100 Exercícios & Conjunto de exercícios & Ensino Médio \\
\hline Adivinha Palavras: Biologia & Conjunto de exercícios & Ensino Fundamental Anos Finais \\
\hline Geração Digital & Livro & $\begin{array}{l}\text { Ensino Fundamental Anos Finais } \\
\text { e Ensino Médio }\end{array}$ \\
\hline PNLD 2015 Moderna & Livro & Ensino Médio \\
\hline Geração Digital 2016 & Livro & Ensino Médio \\
\hline FTD Biologia RA $3^{\circ}$ ano & Livro & Ensino Médio \\
\hline FTD Biologia RA $2^{\circ}$ ano & Livro & Ensino Médio \\
\hline FTD Biologia RA $1^{\circ}$ ano & Livro & Ensino Médio \\
\hline
\end{tabular}




\begin{tabular}{|c|c|c|}
\hline Ciências News - Ciência Channel & $\begin{array}{l}\text { Material de consulta } \\
\text { informações }\end{array}$ & $\begin{array}{l}\text { Ensino Fundamental anos finais e } \\
\text { Ensino Médio }\end{array}$ \\
\hline E-Pesquisa Smartphone & $\begin{array}{l}\text { Material de consulta de } \\
\text { informações }\end{array}$ & $\begin{array}{l}\text { Ensino Fundamental Anos Finais } \\
\text { e Ensino Médio }\end{array}$ \\
\hline Defesa Vegetal & $\begin{array}{l}\text { Material de consulta } \\
\text { informações }\end{array}$ & Ensino Médio \\
\hline Planeta de Peixe & $\begin{array}{lll}\text { Material de consulta } & \text { de } \\
\text { informações }\end{array}$ & Ensino Médio \\
\hline Células do Sangue & $\begin{array}{lll}\text { Material de consulta } & \text { de } \\
\text { informações }\end{array}$ & Ensino Médio \\
\hline Biologia Vestibular Edilson & $\begin{array}{l}\text { Material de consulta de } \\
\text { informações }\end{array}$ & Ensino Médio \\
\hline EV Exames & $\begin{array}{lrl}\text { Material de } & \text { consulta } & \text { de } \\
\text { informações; } & \text { Conjunto } & \text { de } \\
\text { exercícios } & & \end{array}$ & Ensino Médio \\
\hline BlogBlux & Outro (Artigos) & Ensino Médio \\
\hline Animobile - Curiosidades & $\begin{array}{l}\text { Outro (Curiosidades sobre o } \\
\text { mundo da Biologia) }\end{array}$ & $\begin{array}{l}\text { Ensino Fundamental Anos Finais } \\
\text { e Ensino Médio }\end{array}$ \\
\hline Glossário de Biologia & Outro (Dicionário) & Ensino Médio \\
\hline BioMania & Outro (Dicionário) & Ensino Médio \\
\hline Biologia Dicionário & Outro (Dicionário) & Ensino Médio \\
\hline Biotecnologia & Outro (História da Biologia) & Ensino Médio \\
\hline DCL 3D Biologia 2 & $\begin{array}{l}\text { Outro (Imagens do livro em } \\
\text { 3D) }\end{array}$ & Ensino Médio \\
\hline DCL 3D Biologia 1 & $\begin{array}{l}\text { Outro (Imagens do livro em } \\
\text { 3D) }\end{array}$ & $\begin{array}{l}\text { Ensino Fundamental Anos Iniciais } \\
\text { e Finais, Ensino Médio }\end{array}$ \\
\hline Estrela Do Mar Fundo HD & Outro (Imagens) & Todos os níveis \\
\hline InterBio & Outro (Jogo quizz) & $\begin{array}{l}\text { Ensino Fundamental Anos Finais } \\
\text { e Ensino Médio }\end{array}$ \\
\hline MBots - Nanorrobôs Musculares & Outro (Jogo) & Ensino Fundamental anos Iniciais \\
\hline Estudapp Biologia & Outro (Jogo) & Ensino Médio \\
\hline Biologia Divertida & Outro (Jogo) & Ensino Médio \\
\hline Ludo Simulado & $\begin{array}{l}\text { Outro (Jogo); Material de } \\
\text { consulta de informações; } \\
\text { Conjunto de exercícios }\end{array}$ & Ensino Médio \\
\hline GoCongr & Simulador & $\begin{array}{l}\text { Ensino Fundamental Anos Finais } \\
\text { e Ensino Médio }\end{array}$ \\
\hline DNA Sequence & Simulador & Ensino Médio \\
\hline Bio Inc. - Biomedical Game & Simulador & Ensino Médio \\
\hline Anatomia Humana 3D - Grátis & Simulador; Livro & Ensino Médio \\
\hline Sistemas do Corpo Humano 3D & $\begin{array}{l}\text { Simulador; Material de } \\
\text { consulta de informações }\end{array}$ & Ensino Médio \\
\hline Dicionário de Biologia Free & $\begin{array}{l}\text { Simulador; Material de } \\
\text { consulta de informações }\end{array}$ & Ensino Médio \\
\hline Célula & $\begin{array}{l}\text { Simulador; Material de } \\
\text { consulta de informações }\end{array}$ & Ensino Médio \\
\hline Carlos Valença Biologia & $\begin{array}{l}\text { Simulador; Material } \\
\text { consulta de informações }\end{array}$ & Ensino Médio \\
\hline Aminoácidos: Estrutura química & $\begin{array}{l}\text { Simulador; } \\
\text { (Dicionário) }\end{array}$ & Ensino Médio \\
\hline
\end{tabular}




\begin{tabular}{|c|c|c|}
\hline Lab. Interativo de Ciências & $\begin{array}{l}\text { Simulador; } \\
\text { consulta de inforial de } \\
\text { Livro }\end{array}$ & Ensino Médio \\
\hline $\begin{array}{lll}\text { ENEMQuiz } & \text { Questões } & \mathrm{e} \\
\text { Videoaulas } & & \\
\end{array}$ & $\begin{array}{l}\text { Vídeo ou animação; } \\
\text { Conjunto de exercícios }\end{array}$ & Ensino Médio \\
\hline Biologados & $\begin{array}{l}\text { Vídeo ou animação; } \\
\text { Conjunto de exercícios }\end{array}$ & Ensino Médio \\
\hline Teníase e Cisticercose & $\begin{array}{l}\text { Vídeo ou animação; Material } \\
\text { de consulta de informações }\end{array}$ & Ensino Médio \\
\hline Síntese Proteica 2 & $\begin{array}{l}\text { Vídeo ou animação; Material } \\
\text { de consulta de informações }\end{array}$ & Ensino Médio \\
\hline LookBio - Biologia & $\begin{array}{l}\text { Vídeo ou animação; Material } \\
\text { de consulta de informações }\end{array}$ & Ensino Médio \\
\hline Descomplica: Foco no Enem 2016 & $\begin{array}{l}\text { Vídeo ou animação; Material } \\
\text { de consulta de informações }\end{array}$ & Ensino Médio \\
\hline 3D Órgão (anatomia) & $\begin{array}{l}\text { Vídeo ou animação; Material } \\
\text { de consulta de informações }\end{array}$ & Ensino Médio \\
\hline Luiz Renato Me Ajuda & $\begin{array}{lcc}\text { Vídeo } & \text { ou } & \text { animação; } \\
\text { Conjunto de } & \text { exercícios; } \\
\text { Material de consulta de } \\
\text { informações }\end{array}$ & Ensino Médio \\
\hline $\begin{array}{ll}\text { Enem } 2016 & \text { Simulado } \\
\text { Gabaritando } & \end{array}$ & \begin{tabular}{lll} 
Vídeo ou & \multicolumn{2}{c}{ animação; } \\
Simulador; Conjunto & de \\
exercícios; Material & de \\
consulta de informações
\end{tabular} & Ensino Médio \\
\hline
\end{tabular}

Fonte: Dados da Pesquisa.

Emergiram da análise das categorias "temáticas" e "conteúdos" as seguintes subcategorias, que poderão ser utilizados nas estratégias de ensino elaboradas pelos professores: a) Anatomia e Fisiologia Humana (28 apps): Sistema Nervoso, Sistema Digestório, Sistema Circulatório, Sistema Locomotor, Sistema Respiratório; b) Biologia Celular (30 apps): Célula Procarionte, Célula Eucarionte, Célula Vegetal, Célula Animal e Célula Bacteriana; d) Taxonomia dos Seres Vivos (20 apps). Destacamos que 13 apps englobaram as três temáticas (Quadro 2).

Quadro 2 - Temática encontrada em cada app no Google Play Store ${ }^{\circledR}$

\begin{tabular}{|l|l|l|}
\hline \multicolumn{1}{|c|}{ Temática } & \multicolumn{1}{|c|}{ Conteúdos } & \multicolumn{1}{|c|}{ Apps } \\
\hline Biologia & Célula & LookBio - Biologia; Célula; Glossário de Biologia; Biologia 100 \\
Celular & Procarionte, & Exercícios; Dicionário de Biologia Free; Adivinha Palavras: \\
& Célula & Biologia; Passei! ENEM; Biologia Dicionário; Aminoácidos: \\
& Eucarionte, & Estrutura química; Descomplica: Foco no Enem 2016; Bios Cursos; \\
& Célula Vegetal, & Bio Inc. - Biomedical Game; Biologia Vestibular Edilson; BlogBlux; \\
& Célula Animal e & Biomania; Enem 2016 Simulado; Gabaritando; Lab. Interativo de \\
& Célula & Ciências; Brainly - estude com a gente; Síntese Proteica 2; Carlos \\
& Bacteriana & Valença Biologia; Geração Digital 2016; Teníase e Cisticercose; E- \\
& & Pesquisa Smartphone; Geração Digital; Estudapp Biologia; Ludo \\
& & Simulado; EV Exames; DNA Sequence; Ciências News - Ciência \\
& & Channel; Biologia Divertida. \\
\hline
\end{tabular}




\begin{tabular}{|l|l|l|}
\hline $\begin{array}{l}\text { Anatomia } \\
\text { Fisiologia } \\
\text { Humana }\end{array}$ & $\begin{array}{l}\text { Sistema } \\
\text { Nervoso, }\end{array}$ & $\begin{array}{l}\text { Glossário de Biologia; Biologia 100 Exercícios; 3D Órgão } \\
\text { (anatomia); Dicionário de Biologia Free; Adivinha Palavras: }\end{array}$ \\
& Sistema & Biologia; Passei! ENEM; \\
& Digestório, & Sistemas do Corpo Humano 3D; Biologia Dicionário; Descomplica: \\
& Sistema & Foco no Enem 2016; DCL 3D Biologia 1; Anatomia Humana 3D - \\
& Circulatório, & Grátis; Bios Cursos; Biologia Vestibular Edilson; DCL 3D Biologia \\
& Sistema & 2; BlogBlux; Biomania; Enem 2016 Simulado Gabaritando; Brainly \\
& Locomotor, & - estude com a gente; Biologados; Geração Digital 2016; E-Pesquisa \\
& Sistema & Smartphone; Geração Digital; Estudapp Biologia; Ludo Simulado; \\
& Respiratório & EV Exames; Células do sangue; Ciências News - Ciência Channel; \\
& Biologia Divertida. \\
\hline Taxonomia dos seres vivos & LookBio - Biologia; Dicionário de Biologia Free; Passei! ENEM; \\
& Bios Cursos; Biologia Vestibular Edilson; BlogBlux; Enem 2016 \\
& Simulado Gabaritando; Brainly - estude com a gente; Animobile - \\
& Curiosidades; Planeta de Peixe; MBots - Nanorrobôs Musculares; \\
& Teníase e Cisticercose; \\
& E-Pesquisa Smartphone; Biotecnologia; Estudapp Biologia; Defesa \\
& Vegetal; Ludo Simulado; EV Exames; Ciências News - Ciência \\
& Channel; Biologia Divertida. \\
\hline
\end{tabular}

Fonte: Dados da Pesquisa.

A diversidade de apps para o ensino de Ciências e Biologia, gratuitos e em língua portuguesa, representam não apenas avanços tecnológicos como científicos, os quais possibilitam a ampliação dos horizontes educativos não restritos às estratégias de ensino, mas nos próprios processos de ensino e aprendizagem dos alunos e dos professores ${ }^{8}$. A especificação da superação de "[...] pré-conceitos no uso desses dispositivos no âmbito escolar" (DARON; SOARES; BARROS, 2014, p. 479), não se trata apenas de uma abordagem tecnocêntrica das TD, por isso a importância do papel do professor, neste dado momento histórico, social e cultural. Tendo em vista que "a integração das tecnologias aos processos educativos demanda reflexões de caráter mais amplo, que procurem mais a problematização do que a indicação de normas e procedimentos a serem seguidos" (DIAS; PEIXOTO, 2012, p. 221).

Portanto, a integração curricular das tecnologias da informação e comunicação (TIC) está atrelada à própria constituição docente e à apropriação das TD, visando a uma docência com intencionalidade. Ao propiciar as "[...] condições para que o aluno possa fazer as conexões entre os conhecimentos, verificando o 'porquê, o para quê e o como' dos saberes, além de auxiliar na seleção do que realmente vale a pena estudar e esclarecer aquilo que o aprendiz ainda não conseguiu aprender" (SILVA; PAULA, 2012, p. 237). $\mathrm{Na}$ articulação entre os conhecimentos tecnológicos, pedagógicos e de conteúdo,

\footnotetext{
${ }^{8}$ Estes num continuam processo formativo e constitutivo de sua docência (GÜLLICH, 2017).
} 
considerando o contexto específico, o professor desenvolve o TPACK (MISHRA; KOEHLER, 2006).

Ao compreendermos as TD como instrumentos culturais (VIGOTSKI, 2007) ${ }^{9}$, que precisam ser apropriados pelos indivíduos e moldam suas ações (WERTSCH, 1998), ampliamos as possibilidades da própria docência, sua autonomia e autoria no desenvolvimento do currículo. Bem como as concepções sobre teoria e prática numa “[...] via de mão dupla" (GÜLLICH, 2017, p. 22).

Neste sentido, a articulação entre as pesquisas acadêmicas e as práticas docentes também estão inter-relacionadas à autonomia e à autoria curricular dos professores que:

[...] precisam compreender os modelos teóricos e metodológicos da área de conhecimento em que atuam, mas também precisam participar ativamente da atualização desses modelos na medida em que o contexto vai exigindo a superação das práxis e lhes conferindo novos desafios formativos (DARON; SOARES; BARROS, 2014, p. 486).

Vislumbramos que os estudos a exemplo deste - uma proposta de uso de apps visando à articulação da mobile learning aos aspectos do currículo e didática das Ciências e Biologia, bem como a formação e a constituição docente, permite a superação de visões simplistas de ensino e docência (CARVALHO; GIL-PÉREZ, 2001) e a compreensão do papel das TD nestes processos, possibilitando a aproximação entre Educação Básica e Superior. Ao discutirmos os processos formativos considerando a integração curricular das TD, podemos desenvolver processos de ensino e aprendizagem, assumindo a sua inter-relação nos processos socioculturais (DIAS; PEIXOTO, 2012).

\section{Mobile learning e o trabalho com apps no ensino de Ciências: necessidades} formativas e educacionais

Apresentamos uma análise de apps como proposta para o desenvolvimento da mobile learning na docência dos professores de Ciências e Biologia da Educação Básica. Consideramos que a publicização desta análise ilustra possibilidades de elaboração de estratégias para o ensino de Ciências. Os apps e outras TD são instrumentos culturais,

\footnotetext{
${ }^{9}$ Os instrumentos culturais orientam as ações e os processos de desenvolvimento do indivíduo pelas interações entre sujeitos, envolvendo a mediação. Estas relações possibilitam o desenvolvimento das funções psicológicas devido aos efeitos nas estruturas mentais superiores
} 
presentes em nossos contextuais atuais, que precisam ser inseridos nas instituições de ensino. Depreendemos que os dispositivos móveis e seus apps, no desenvolvimento da mobile learning, podem ser instrumentos potentes para contribuir com a melhoria e ampliação da aprendizagem, principalmente para os alunos que tradicionalmente não tinham acesso à educação, por questões geográficas, econômicas e sociais (SCHLEMMER, et al., 2007; TRAXLER, 2008).

O uso de apps atrelado a mobile learning podem favorecer o desenvolvimento dos conhecimentos de nossos alunos nos distintos contextos educacionais, tanto na Educação Básica como na Superior. Se inseridos de modo intencional, ao nos apropriarmos dos apps considerando suas características de utilização de maneira intuitiva e interface de fácil manuseio, poderemos estender as possibilidades em contexto escolar e as interações entre professores e alunos visando ao ensino e aprendizagem de Ciências.

Estamos cientes dos desafios para a implementação desta proposta de uso de apps na construção de estratégias de ensino na Educação Básica. Principalmente em relação ao acesso à internet, que depende de uma infraestrutura tecnológica adequada diferenciada, de acordo com cada contexto educativo específico. Outra situação, que precisa ser problematizada nas escolas brasileiras, refere-se à proibição do uso de celulares em sala de aula, pois o uso das TIMS, nas escolas brasileiras, aponta para um crescente número significativo; entretanto, é necessário romper com a barreira da proibição do uso dessas tecnologias, especialmente os smartphones no âmbito escolar, para que assim os professores e alunos utilizem os apps em sala de aula nas mais diversas áreas do ensino (NICHELE, 2015).

Neste sentido, consideramos como elemento de fortalecimento para a superação destas adversidades, uma formação de professores que considere a necessidade da docência num trabalho com as TD. Como passo inicial, é premente:

[...] que os professores atribuam sentidos, signifiquem o uso, no que se refere ao seu próprio processo de aprendizagem, estando esse processo fundamentado numa perspectiva mais ampla, que envolve antes, uma clareza epistemológica no que se refere à compreensão de como os sujeitos aprendem na interação com esses dispositivos e aplicativos, na relação com as especificidades da área do conhecimento [...], para que dessa forma, possam desenvolver metodologias, práticas e processos de mediação pedagógica capazes de provocar mudanças significativas na forma de se ensinar e de aprender, considerando as especificidades desses dispositivos, bem como o contexto da mobilidade (NICHELE; SCHLEMMER, 2014, p. 8). 
O planejamento adequado com o uso de apps, previamente selecionados e avaliados pelo professor, será decorrente desta significação e apropriação do uso das TD nas estratégias de ensino. Para tanto, é necessário romper com a visão tecnocêntrica sobre as TD e a sua relação nos processos de ensino e aprendizagem, em todos os níveis educacionais: na Educação Básica e no Ensino Superior, na formação inicial e continuada de professores. Depreendemos que o desenvolvimento do TPACK será essencial no processo constitutivo dos professores de ciências, num trabalho de integração das TD, considerando os contextos educativos específicos.

\section{Considerações Finais}

Ao publicizarmos a análise de apps como proposta para a elaboração de estratégias de ensino de Ciências com a mobile learning, compartilhamos nossos pressupostos teóricos e resultados de pesquisa e formação de professores, visando a uma aproximação entre Educação Básica e a pesquisa em Educação nas Ciências advinda do Ensino Superior, premissa já defendida por Carvalho e Gil-Pérez (2001), como forma de superar as compreensões simplistas de ensino e de docência em Ciências.

$\mathrm{O}$ arcabouço teórico e o respaldo de nossa produção de resultados embasam as pesquisas acadêmicas desenvolvidas em nosso grupo de estudos e pesquisas que são compartilhados, vivenciados e experienciados, visando à constituição dos conhecimentos necessários aos professores de Ciências, em processos de formação inicial e continuada. Neste sentido, entendemos ser potente a utilização de apps e a mobile learning nos contextos educativos, como demonstrado nesta pesquisa.

\section{Referências}

ALCÂNTARA, N. R.; MORAES FILHO, A.V. Elaboração e utilização de um aplicativo como ferramenta no ensino de bioquímica: carboidratos, lipídios, proteínas e ácidos nucleicos. Revista de Ensino de Bioquímica, São Paulo, v. 13, n. 3, p. 54-72, 2015. Disponível em: http://bioquimica.org.br/revista/ojs/index.php/REB/article/view/560/518. Acesso em: 04 jun. 2019.

ALMEIDA, R. R.; ARAÚJO JR, C. F.; FRANÇA, M. P. O uso do tablet para a representação de conceitos de genética: proposta e análise com base na Teoria da Atividade. Renote - Revista Novas Tecnologias na Educação, Porto Alegre, v. 13, n. 1, p. 1-11, 2015. Disponível em: http://www.seer.ufrgs.br/index.php/renote/article/view/57635/34603. Acesso em: 03 jun. 2019. 
BARROS, M. A. de M. Concepções, usos, modelos e estratégias da utilização de dispositivos móveis: uma análise da Aprendizagem Móvel entre professores de Ciências em formação. 2014. 241 f. Tese (Doutorado) - Curso de Programa de Pós-graduação em Ensino das Ciências da Universidade Federal Rural de Pernambuco, Universidade Federal Rural de Pernambuco, Recife, 2014. Disponível em: http://www.ppgec.ufrpe.br/sites/www.ppgec.ufrpe.br/files/documentos/tese_marcosbarros.pdf. Acesso em: 05 jun. 2019

CÂMARA DOS DEPUTADOS. Lei N. ${ }^{o}$ 2.246, 2007. Disponível em: http://www.camara.gov.br/proposicoesWeb/prop_mostrarintegra?codteor=517286\&file name=Avulso+-PL+2246/2007. Acesso em: 03 jun. 2019.

CARVALHO, A. M. P. de; GIL-PÉREZ, D. Formação de professores de ciências. São Paulo: Cortez, 2000. 120p.

DARON, E.C. de A. S. K.; SOARES, E. C.; BARROS, M. P. Espia lá - Mato Grosso aplicativo educacional em dispositivo móvel para a formação continuada de professores. Revista Polyphonía, Goiânia, v. 25, n. 2, p. 475-487, 2014. Disponível em: https://www.revistas.ufg.br/sv/article/view/38157/19312. Acesso em: 12 jun. 2019.

DIAS, D. R.; PEIXOTO, J. Formação de professores de matemática e o uso das Tecnologias de Informação e Comunicação: entre uma abordagem instrumental e determinista. Revista Polyphonía, Goiânia, v. 23, n. 2, p. 219-235, 2012. Disponível em: https://www.revistas.ufg.br/sv/article/view/33923/17950. Acesso em: 12 jun. 2019.

FERNANDES, F. G. et al. Ensino da anatomia do corpo humano usando a realidade aumentada móvel. In: CONFERÊNCIA DE ESTUDOS EM ENGENHARIA ELÉTRICA, 11º, 2013, Uberlândia. Anais... Uberlândia: Ceel, 2013. p. 1 - 6. Disponível em: https://www.peteletricaufu.com/static/ceel/doc/artigos/artigos2013/ceel2013_025.pdf. Acesso em: 05 jun. 2019.

GÜLLCH, R. I. da C. O livro didático, o professor e o ensino de ciências: um processo de investigaçãoformação-ação. 2012. 263 f. Tese (Doutorado) - Curso de Pós-graduação em Educação nas Ciências, Universidade Regional do Noroeste do Estado do Rio Grande do Sul, Jjuí, 2012. Disponível em: http:/bibliodigital.unijui.edu.br:8080/xmlui/bitstream/handle/123456789/2043/Roqueda\%20Costa\%20G\%C 3\%BCllich.pdf?sequence=1. Acessoem: 30 out. 2019.

GÜLLICH, R. I da C. Formação em Ciências e em Biologias: discutindo requisitos de um processo didático. Em GÜLLICH, R. I da C.; HERMEL, E. do E. (Orgs.). Didática da Biologia. Curitiba, PR: APPRIS, 2017., p. 13-26

MISHRA, P.; KOEHLER, M. J. Technological Pedagogical Content Knowledge: a framework for teacher knowledge. Teachers College Record, Nova York, v. 108, n. 6, p. 1017-1054, 2006. 
NICHELE, A. G. Tecnologias móveis e sem fio nos processos de ensino e de aprendizagem em química: uma experiência no Instituto Federal de Educação, Ciência e Tecnologia do Rio Grande do Sul. 2015. 257 f. Tese (Doutorado) - Curso de Programa de Pós-graduação em Educação, Universidade do Vale do Rio dos Sinos, São Leopoldo, 2015. Disponível em: http://www.repositorio.jesuita.org.br/bitstream/handle/UNISINOS/3754/Aline\%20Grunewald\%2 0Nichele.pdf?sequence=1\&isAllowed=y> Acesso em: 02 jun. 2019.

NICHELE, A. G.; SCHLEMMER,E. Aplicativos para o ensino e aprendizagem de Química. Renote - Revista Novas Tecnologias na Educação, Porto Alegre, v. 12, n. 2, p. 1-9, 2014. Disponível em: http://seer.ufrgs.br/index.php/renote/article/view/53497/33014. Acesso em: 02 jun. 2019.

ROCHA, M. D. et al. (Des) liga esse celular, moleque!: Smartphone como minilaboratório no ensino de ciências. Revista Monografias Ambientais - Remoa, Santa Maria, v. 14, n. 1, p. 41-52, 2015. Disponível em: http://cascavel.cpd.ufsm.br/revistas/ojs2.2.2/index.php/remoa/article/view/20435/pdf. Acesso em: 04 jun. 2019.

SCHLEMMER, E. et al. M-learning ou aprendizagem com mobilidade: casos no contexto brasileiro. In: CONGRESSO INTERNACIONAL DE EDUCAÇÃO A DISTÂNCIA, 13., 2007, Curitiba. Anais... Curitiba: Abed - Associação Brasileira de Educação A Distância, 2007. p. 1 - 11. Disponível em: http://www.abed.org.br/congresso2007/tc/552007112411PM.pdf. Acesso em: 02 jun. 2019.

SILVA, N. M.; PAULA, M. V. Escola e cibercultura: breve reflexão acerca do uso das TIC como recurso pedagógico. Revista Polyphonía, Goiânia, v. 23, n. 1, p. 231-240, 2012. Disponível em: https://www.revistas.ufg.br/sv/article/view/26700/15295. Acesso em: 12 jun. 2019.

TRAXLER,J. Mobility, Modemity, Development. In: INTERNATIONALCONFERENCEONMOBILE COMMUNICATIONTECHNOLOGY FOR DEVELOPMENT, 1., 2008, Karlstad. Proceedings of M4D 2008. Karlstad: Karlstads Universitet, 2008. p. 93-99. Disponível em: http://is.ukzn.ac.za/Libraries/IST2011/M4D2008_Traxler.sflb.ashx. Acesso em:07 jun 2019.

TRAXLER, J. Defining, Discussing, and Evaluating Mobile Learning: The moving finger writes and having writ... International Review Of Research In Open And Distance Learning, Athabasca, v. 8, n. 2, p. 1-12, 2007. Disponível em: http://www.irrodl.org/index.php/irrodl/article/view/346/875. Acesso em: 04 jun 2019.

TRAXLER, J. Mobile Learning - The Future Already Behind Us: A Review and Analysis of the Bigger Picture. In: INTERNATIONAL CONFERENCE ON INTERACTIVE MOBILE AND COMPUTER AIDED LEARNING (IMCL), 7., 2012, Amã. Proceedings of 2012 International Conference on Interactive Mobile and Computer Aided Learning. Amã: Institute Of Electrical And Electronics Engineers (IEEE), 2012. p. 7 - 9. Disponível em: https://ieeexplore.ieee.org/stamp/stamp.jsp?arnumber=6396442. Acesso em: 03 jun 2019.

TRAXLER, J.; VOSLOO, S. Introduction: The prospects for mobile learning. Prospects, [s.l.], v. 44, n. 1, p. 13-28, 2014. Springer Nature. http://dx.doi.org/10.1007/s11125-0149296-z. Disponível em: https://link.springer.com/content/pdf/10.1007/s11125-014-9296z.pdf. Acesso em: 05 jun 2019. 
VIGOTSKI, L. S. A formação social da mente. 7. ed. São Paulo: Martins Fontes, 2007. p. 182.

WERTSCH, J. V. A necessidade da ação na pesquisa sociocultural. Em WERTSCH, J. V.; DEL RÍO, P.; ALVAREZ, A. (Orgs.). Estudos socioculturais da mente. Porto Alegre, RS: ArtMed, 1998, p. 56-71.

ZANON, L. B. Interações de licenciandos, formadores e professores na elaboração conceitual de prática: módulos triádicos na licenciatura de Química. 294 p. Tese (Doutorado) - Curso de Pós-Graduação em Educação, Universidade Metodista de Piracicaba, Piracicaba, 2003.

Recebido em: 23 ago. 2019.

Aceito em: 12 nov. 2020. 